Case Report

J Exp Clin Med

2021; 38(4): 689-692

doi: $10.52142 /$ omujecm.38.4.51

\title{
A rare case: pulmonary thromboembolism and pneumothorax coexistence secondary to Covid-19 infection
}

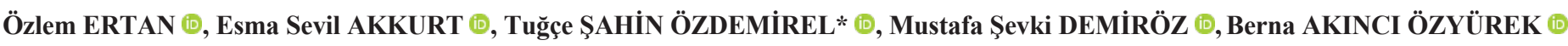 \\ Department of Chest Disease, Atatürk Chest Diseases and Chest Surgery Training and Research Hospital, University \\ of Health Sciences, Ankara, Turkey
}

\begin{tabular}{l}
\hline Received: $11.03 .2021 \quad$ Accepted/Published Online: 26.03 .2021 \\
\hline Abstract \\
Acute respiratory disease caused by a novel coronavirus (Serious Acute Respiratory Syndrome-Coronavirus-2) type that was first detected in \\
Wuhan, Hubei Province of China, has turned into a pandemic. The disease commonly presents with fever, cough, and malaise, and typically \\
bilateral peripheral ground-glass areas are seen in thorax computed tomography. While it may present as mild upper respiratory tract infection or \\
pneumonia, patients may also develop pulmonary thromboembolism and pneumothorax. In our case, in a young male patient who was followed \\
up for severe pneumonia due to COVID-19 infection, pulmonary thromboembolism, parenchymal cysts, and pneumothorax were detected. \\
Although pulmonary thromboembolism is a common complication, cyst formation and pneumothorax are rare. We aimed to present this case \\
because of the coexistence of multiple pulmonary complications despite the young age of the patient.
\end{tabular}

Keywords: COVID-19, pulmonary thromboembolism, pneumothorax, complication

\section{Introduction}

At the end of 2019, a new coronavirus subtype was identified in cases with pneumonia in Wuhan, Hubei Province of China, and the novel type of coronavirus infection, which turned into an epidemic in other provinces of China, was officially declared as an international public health emergency of concern by the World Health Organization (WHO) on January 30, 2020. In February 2020, the new type of coronavirus infection was named Serious Acute Respiratory Syndrome-Coronavirus-2 (SARS-CoV-2), and the disease it caused as COVID-19 (Corona Virus Disease 2019) by WHO (1). On thoracic computed tomography (CT), bilateral multilobar ground-glass opacities, consolidation, flagstone appearance, air cysts, nodules, halo and reverse halo sign, bronchial dilatation and pulmonary vascular enlargement can be seen, which are more significant in peripheral or posterior of the lungs (2). COVID-19 infection may present as an upper respiratory tract infection, as well as a severe disease such as acute respiratory distress syndrome (ARDS) and septic shock. (3). We aimed to present our case who developed hydropneumothorax and pulmonary thromboembolism (PTE) after COVID-19 pneumonia.

\section{Case report}

The thirty-five-year-old male patient was admitted to another hospital due to COVID-19 pneumonia, and upon the development of pulmonary thromboembolism and hydropneumothorax, he was transferred to our center for further follow-up of thoracic diseases and thoracic surgery departments. The anamnesis of the patient revealed, he had complaints of cough and right flank pain that started three days before his admission to the hospital, he was a metal worker and he did not have a history of smoking or an additional disease. The patient's Reverse-Transcriptase Polymerase Chain Reaction (RT-PCR) test which was done upon admission was positive, there was bilateral pneumonia in chest radiography (Fig. 1) and the laboratory findings were as follows: lymphocyte count $1950 / \mu 1$, ferritin $1381 \mathrm{ng} / \mathrm{ml}, \mathrm{C}$ reactive protein (CRP) $154 \mathrm{mg} / \mathrm{L}, \mathrm{D}$ - dimer $9.94 \mathrm{mg} / \mathrm{L}, \mathrm{LDH}$ 450 IU/L. Pulmonary thorax computed tomography angiography (CTA) and thorax CT were performed because of the development of chest pain with a stabbing character on the 2nd day of hospitalization while receiving prophylactic dose low molecular weight heparin (LMWH) and COVID-19 pneumonia treatment (favipiravir and ceftriaxone). The CTA revealed appearance compatible with segmental pulmonary thromboembolism in the lower lobe of the right lung, bilateral multilobar ground glass, and consolidated areas, multiple increased nodular densities, unilateral pleural effusion on the right (Fig. 2). While the patient was receiving treatment for PTE and COVID-19 pneumonia, on the 17th day, due to the development of severe dyspnea and deterioration in general condition, chest radiography was performed and an appearance compatible with hydropneumothorax was observed, so he was transferred to our hospital with the diagnosis of PTE, COVID-19 pneumonia and hydropneumothorax. 


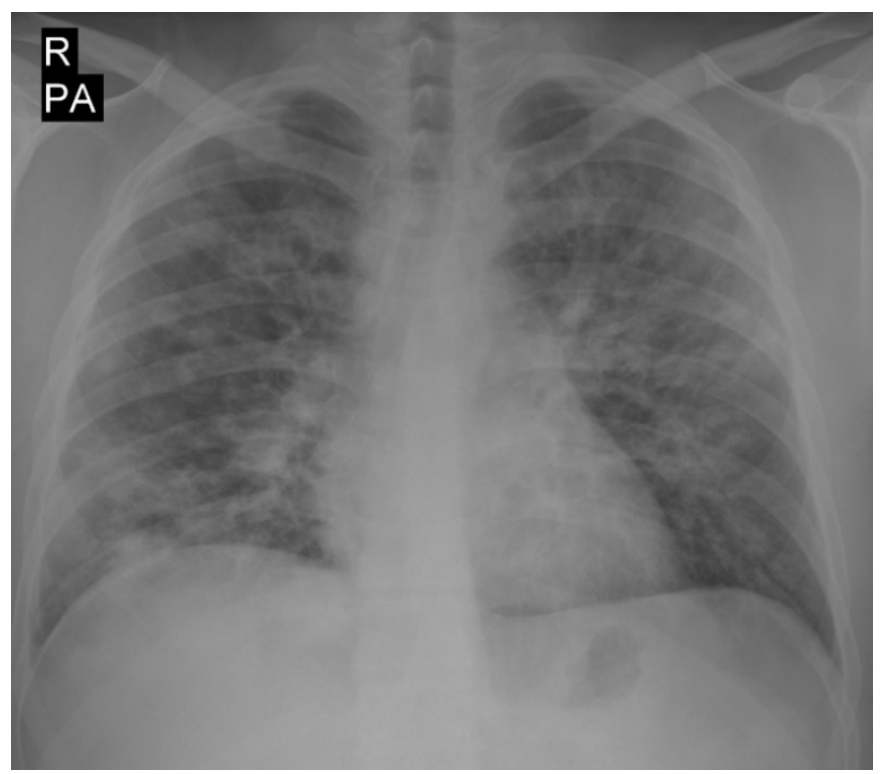

Fig. 1. Bilateral pneumonia in posteroanterior chest radiography
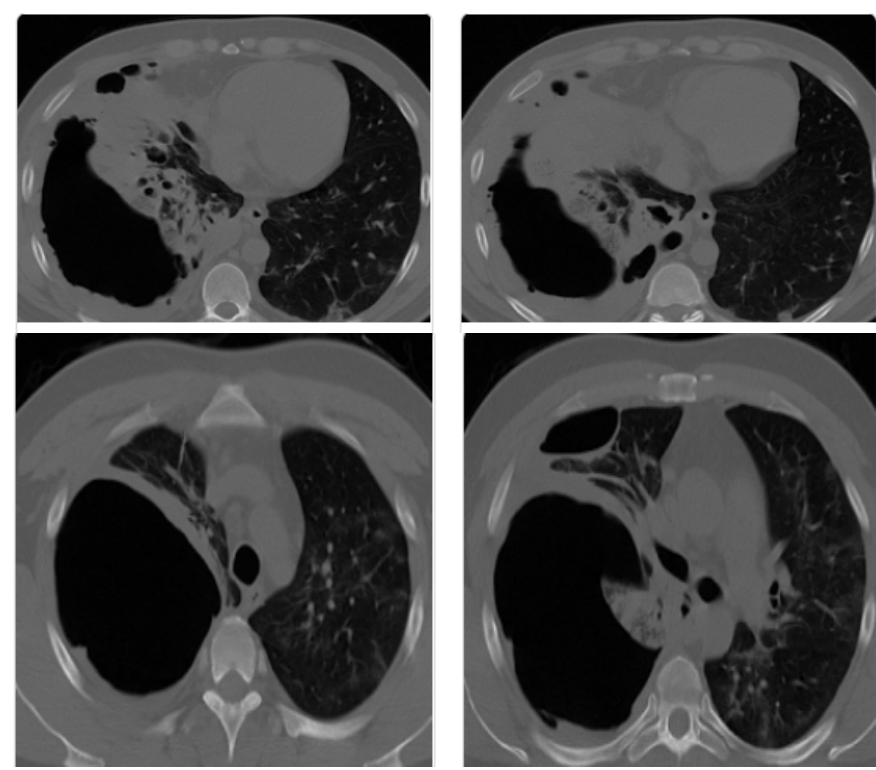

Fig. 2. Hydropneumothorax and COVID-19 pneumonia

In the physical examination of the patient, the respiratory sound was missing in the right lung, and the saturation was measured as $95 \%$ under $5 \mathrm{~L} / \mathrm{min}$ oxygen support with a nasal cannula. Other system examinations were normal. In the laboratory findings, lymphocyte count was $1850 / \mu 1$, ferritin $1170 \mathrm{ng} / \mathrm{ml}$, CRP $89 \mathrm{mg} / \mathrm{L}$, D-dimer $7.82 \mathrm{~m} \mathrm{/L}$, and LDH $305 \mathrm{IU} / \mathrm{L}$. Chest radiography revealed an increase in nonhomogeneous density in the upper-middle zone of the left lung and an appearance compatible with hydropneumothorax in the right lung. The patient who was consulted by the thoracic surgery department underwent tube thoracostomy through the mid-axillary right $7^{\text {th }}$ intercostal space under local anesthesia. After one day of follow-up, subcutaneous emphysema developed in the patient whose lungs were not fully expanded. Thoracic surgery was consulted again. A second tube thoracostomy was performed on the patient through the $3^{\text {rd }}$ intercostal space on the right midclavicular line and a pessary tube was placed under local anesthesia. Later, it was observed that the lung was expanded, however, the progression in subcutaneous emphysema was detected in the patient whose massive air leak continued. On the $4^{\text {th }}$ day after the insertion of a chest tube, a sore throat and facial swelling developed in the patient. In the physical examination, crepitation was also taken in the neck and face. After COVID-19 PCR test was detected negative twice, the patient was transferred to thoracic surgery for further treatment. During the follow-up in the thoracic surgery ward, the tube was terminated since there was no air discharge from the first chest tube inserted. Pleurodesis was performed in the patient whose air discharge continued through the pesser drain. During the 14-day follow-up in the thoracic surgery ward, the patient's subcutaneous emphysema and air discharge from the drain gradually decreased, and the antibiotic and LMWH treatments were continued. It was observed that the ground-glass infiltrates persisted but decreased, however, pleural thickening areas developed and partially consolidated areas in the lower lobes were present, in the thoracic tomography. The drain of the patient was taken to Heimlich Valve and discharged when his clinic stabilized, and his symptoms regressed. No complications were observed on the $3^{\text {rd }}$ day after discharge in the outpatient clinic control.

\section{Discussion}

The COVID-19 pandemic started in China in December 2019 and spread all over the world, is a serious health problem that concerns all countries. The COVID-19 infection causes the development of many complications, especially in the respiratory and cardiovascular systems (4). Studies have reported that pulmonary thromboembolism is seen between $10 \%$ and $28 \%$ of the cases. The mean age range of patients with thromboembolism has been given as 57 to 61 years (5, 6). Besides, it been shown to cause spontaneous pneumothorax, and I BV F F'ts incidence is around 1\% (7). There are also publications in the literature reporting that it is seen less frequently (8). Contrary to the literature, the age of our patient was younger, PTE and pneumothorax coexisted together. It has been observed that in these patients, pneumothorax developed after invasive mechanical ventilation, the patients were reported to have more than one pre-existing cardiopulmonary comorbidity (9). Studies have reported that prolonged mechanical ventilator therapy increases the incidence of pneumothorax (10). Our case didn't require mechanical ventilation and being followed up in the ward.

While spontaneous pneumothorax often develops secondary to cystic lung lesions, the mechanism in COVID19 infection is less understood. The known risk factors for spontaneous pneumothorax include male gender, thin and long body structure, smoking, trauma, and infection (11). In contradiction, our case did not have a history of smoking, and pneumothorax developed while being treated in the ward. In addition, no parenchymal lesions such as cyst or bulla were observed in the first thoracic CT of our patient. In the literature, a case that developed giant bulla as a result of 
COVID-19 infection which caused rupture and pneumothorax (12), and a case with cystic lung lesions developed due to COVID-19 infection and caused pneumothorax was published by Liu $\mathrm{k}$ et al. were reported (13). In COVID-19 infection, it is thought that the inflammatory response and ischemic damage in the lung parenchyma cause cell adhesion between type I and type II pneumocytes, alveolar damage, and predispose to subsequent rupture (13). In a report, in which autopsy was performed on two patients who developed pneumothorax and pneumomediastinum after COVID-19 infection and subsequently died due to resistant hypoxemia, diffuse alveolar damage, active infarction, reactive pneumocytes, sparse lymphoplasmacytic inflammation, fibrin thrombus, and multinucleated giant cells were observed histopathologically. Since ventilation and perfusion were both affected concurrently, it is thought to lead to pulmonary tissue ischemia by significantly increasing the degree of hypoxemia and shunt, worsening the perfusion, and increasing the risk of air leak (14). Besides, it is believed that direct viral infiltration of the lung parenchyma, visceral and parietal pleura leads to the development of pneumothorax/pneumomediastinum by causing disruption of parenchymal and pleural integrity or alveolar rupture $(14,15)$. The severity of the symptoms may contribute to alveolar cystic rupture by increasing the respiratory effort due to the ventilation/perfusion imbalance and leading to coughing. Therefore, we think that the development of ischemic parenchymal damage and pulmonary thromboembolism may have caused the development of pneumothorax in our patient. Previous studies have shown that in COVID-19 patients with the critical disease, pneumothorax, pneumomediastinum, and subcutaneous emphysema may contribute to deep hypoxemia, and it is reported as a poor prognostic factor $(14,16)$. It is thought that the most serious problem is pneumothorax and accompanying pneumomediastinum since chronic problems usually occur after the 10th day of the disease and cause a life-threatening risk (17). In the study of 3000 patients by Massa Zantah et al., the presence of lymphopenia and increased inflammatory markers including CRP, LDH, ferritin, D-Dimer, and IL-6 levels were reported in almost all patients who developed a spontaneous pneumothorax (8). In our case, inflammatory parameters were high when pneumothorax developed. The laboratory results of our patient were concurrent with the literature.

Our case had spontaneous pneumothorax and PTE which was caused by COVID-19 pneumonia. It may occur at the beginning of the symptoms or in later stages. It should be kept in mind that complications such as pneumothorax or pulmonary thromboembolism may have developed in cases of acute worsening with rapid oxygen desaturation, newly developing dyspnea, and pleuritic chest pain.

\section{Conflict of interest}

We declare that there is no conflict of interest, in particular no financial funding potentially relevant to the contents of manuscript.

\section{Acknowledgments}

None to declare.

\section{References}

1. World Health Organization. Director-General's remarks at the media briefing on 2019-nCoV on 11 February [Internet] 2020 [updated 2020 Feb 10; cited 2020 Feb 12] Available from: https://www.who.int/dg/speeches/detail/who-director-general-sremarks-at-the-media-briefing-on-2019-ncov-on-11-february2020.

2. Comert SS and Nesrin K. Radiological Findings of COVID-19 Pneumonia. South Clin Ist Euras 2020;31(Suppl):16-22.

3. Li X, Li T, Wang H. Treatment and prognosis of COVID-19: Current scenario and prospects (Review). Exp Ther Med. 2021 Jan;21(1):3. doi: 10.3892/etm.2020.9435.

4. Vakili K, Fathi M, Pezeshgi A, Mohamadkhani A, Hajiesmaeili M, Rezaei-Tavirani M, et al. Critical complications of COVID19: A descriptive meta-analysis study. Rev Cardiovasc Med. 2020 Sep 30;21(3):433-442. doi: 10.31083/j.rcm.2020.03.129.

5. Porfidia A, Valeriani E, Pola R, Porreca E, Rutjes AWS, Di Nisio M. Venous thromboembolism in patients with COVID-19: Systematic review and meta-analysis. Thromb Res. 2020; 196:67-74. doi: 10.1016/j.thromres.2020.08.020.

6. Boonyawat $\mathrm{K}$, Chantrathammachart $\mathrm{P}$, Numthavaj $\mathrm{P}$, Nanthatanti $\mathrm{N}$, Phusanti S, Phuphuakrat A, et al. Incidence of thromboembolism in patients with COVID-19: a systematic review and meta-analysis. Thromb J. 2020 Nov 23;18(1):34. doi: 10.1186/s12959-020-00248-5.

7. Chen N, Zhou M, Dong X, Qu J, Gong F, Han Y, et al. Epidemiological and clinical characteristics of 99 cases of 2019 novel coronavirus pneumonia in Wuhan, China: a descriptive study. Lancet. 2020 Feb 15;395(10223):507-513. doi: 10.1016/S0140-6736(20)30211-7.

8. Zantah M, Dominguez Castillo E, Townsend R, Dikengil F, Criner GJ. Pneumothorax in COVID-19 disease- incidence and clinical characteristics. Respir Res. 2020 Sep 16;21(1):236. doi: 10.1186/s12931-020-01504-y.

9. do Lago VC, Cezare TJ, Fortaleza CMCB, Okoshi MP, Baldi BG, Tanni SE. Does COVID-19 Increase the Risk for Spontaneous Pneumothorax? Am J Med Sci. 2020 Dec;360(6):735-737. doi: 10.1016/j.amjms.2020.07.024.

10. Gattinoni L, Chiumello D, Caironi P, Busana M, Romitti F, Brazzi L, et al. COVID-19 pneumonia: different respiratory treatments for different phenotypes? Intensive Care Med. 2020 Jun;46(6):1099-1102. doi: 10.1007/s00134-020-06033-2.

11. Akgül AG. Pnömotoraks. Journal of Clinical and Analytical Medicine, 55: 2.

12. Sun R, Liu H, Wang X. Mediastinal Emphysema, Giant Bulla, and Pneumothorax Developed during the Course of COVID-19 Pneumonia. Korean J Radiol. 2020 May;21(5):541-544. doi: 10.3348/kjr.2020.0180.

13. Liu K, Zeng Y, Xie P, Ye X, Xu G, Liu J, et al. COVID-19 with cystic features on computed tomography: A case report. Medicine (Baltimore). 2020 May;99(18):e20175. doi: 10.1097/MD.0000000000020175.

14. Tucker L, Patel S, Vatsis C, Poma A, Ammar A, Nasser W, et al. Pneumothorax and Pneumomediastinum Secondary to COVID19 Disease Unrelated to Mechanical Ventilation. Case Rep Crit Care. 2020 Nov 23;2020:6655428. doi: 10.1155/2020/6655428.

15. Hameed M, Jamal W, Yousaf M, Thomas M, Haq IU, Ahmed S, 


\section{Ertan et al. / J Exp Clin Med}

et al. Pneumothorax In Covid-19 Pneumonia: A case series. Respir Med Case Rep. 2020; 31:101265. doi: 10.1016/j.rmcr.2020.101265.

16. Alharthy A, Bakirova GH, Bakheet $\mathrm{H}$, Balhamar A, Brindley PG, Alqahtani SA, et al. COVID-19 with spontaneous pneumothorax, pneumomediastinum, and subcutaneous emphysema in the intensive care unit: Two case reports. J Infect Public Health.
2021 Mar;14(3):290-292. doi: 10.1016/j.jiph.2020.12.019.

17. Demirel Kaya HS, Mammadov O, Doğan L, Sarıkaya ZT, Kısa Özdemir İ, Rasimoğlu S, et al. Standart Protokolile Tedavi Edilen COVID-19 Pnömonisi Hastaları: Beş Yoğun Bakım Ünitesinin Gözlemsel Sonuçları Turk J Intensive Care. 2020; 18:1-13 doi: 10.4274/tybd.galenos.2020.57441. 